\title{
Teaching Mathematical Modelling and Problem Solving - A Cognitive Apprenticeship Approach to Mathematics and Engineering Education
}

\author{
http://dx.doi.org/10.3991/ijep.v4i5.3555 \\ D. Wedelin, T. Adawi \\ Chalmers University of Technology, Gothenburg, Sweden
}

\begin{abstract}
We describe a course in mathematical modelling and problem solving, intended to provide the students with the appropriate skills to deal with real world problems in science and technology. The course is inquiry-based and centered around approximately 30 reasonably realistic, highly varied and challenging problems, which are solved in pairs. The students are supervised in a cognitive apprenticeship environment, where the teacher uses a range of techniques to align student thinking with expert thinking. After taking the course, most students express and demonstrate a fundamental change in their abilities to think mathematical$l y$, in their understanding of the nature of mathematics and its role in their future profession. They also consider it as one of the most important courses in their education. We therefore argue that this kind of course, or similar teaching, should be present in the engineering curriculum.
\end{abstract}

Index Terms-mathematical modelling, problem solving, inquiry-based learning, cognitive apprenticeship, mathematics, engineering education

\section{INTRODUCTION}

In this paper, we describe the design of a course in mathematical modelling and problem solving, given to second year students in Software Engineering and related programmes at Chalmers University of Technology, Sweden (see [1] for details of the course). The overall aim of the course is to provide examples of the application of mathematics, and to improve essential skills needed to deal with real-world problems in science and technology. The course therefore focuses on mathematical modelling, i.e. the ability to translate real-world problems into mathematical problems, and problem solving, which we interpret as the ability to systematically approach and solve non-trivial problems. The importance of teaching such skills to engineering students has been clearly stated, see e.g. [2] and [3]. The overall message, based on educational research, is that "although contents are still important, they should be embedded in a broader view of mathematical competencies that the mathematical education of engineers strives to achieve" [2].

The course was developed by the first author as a response to the observation that many of our students lack appropriate skills to use mathematics in practice, and that neither traditional mathematics courses nor traditional engineering courses appear to seriously and systematically address this issue. This observation is echoed in the literature on engineering education [3]. We see two important reasons for this lack of ability to connect theory and practice - in general - among engineering students. Firstly, engineering education has been criticised for teaching knowledge and skills in an abstract way, which makes it difficult for students to apply what they have learned to real-world situations [4]. Secondly, teachers seldom explain and demonstrate the entire problem solving process, including assumptions, alternative strategies and evaluation of results [5]. As a consequence, and returning to the example of mathematics education, engineering students often fail to connect and apply what they have learned in introductory mathematics courses to other subjects [6], sometimes leading to the belief that mathematics is not relevant for them [7].

While the course was originally designed intuitively and based on experience, we have come to find the notions of inquiry-based learning [8] and cognitive apprenticeship [9] helpful in order to explain both the role of the course in the engineering curriculum, and the philosophy of the course itself. In fact, cognitive apprenticeship was proposed as a solution to the two educational problems described above. As Collins et al. [9] put it in their original paper on cognitive apprenticeship: "It is this dual focus on expert processes and situated learning that we expect to help solve the educational problems of brittle skills and inert knowledge".

The purpose of this paper is to highlight the importance of mathematical modelling and problem solving in the engineering curriculum, and to show how these skills can be successfully taught. In Section II we outline the key ideas in inquiry-based learning and cognitive apprenticeship. Section III discusses mathematical modelling and problem solving. In Section IV we turn to a more detailed description of the course while highlighting connections to inquiry-based learning and cognitive apprenticeship. Section $\mathrm{V}$ describes some examples of problems from the course and how they are used. In Section VI we discuss student impressions of the course and some own experiences, and in Section VII we conclude why a course like this is useful.

\section{INQUIRY BASED LEARNING AND COGNITIVE APPRENTICESHIP}

Inquiry-based learning is an approach to teaching and learning that "uses questions and problems to provide contexts for learning" [8]. The approach is inductive in that it is based on specific tasks and only thereafter progresses towards theories, rather than deductive which is based on theories and progresses towards applications of those theories. A well-known special form of inquirybased learning is problem-based learning (PBL), which 
PAPER

Teaching Mathematical Modelling And Problem Solving - A Cognitive ApPrenticeship ApProach to...

usually emphasizes larger real world problems, and work in larger groups. A relevant observation for us is that to learn a skill, which is not fully described by any theory, an inductive approach is necessary. And the problems must present such challenges that the skills to be learned are actually practised.

Cognitive apprenticeship was developed by Collins et al. [9], and has roots in situated learning theory [10]. It is based on the observation that apprenticeship, or learning through guided experience, "is the way we learn most naturally". The idea is to adapt traditional apprenticeship, to teach such cognitive skills and processes that experts use when dealing with authentic, complex tasks. According to [11], "a major advantage of learning by cognitive apprenticeship as opposed to traditional classroom-based methods is the opportunity to see the subtle, tacit elements of expert practice that may not otherwise be explicated in a lecture or knowledge-dissemination format". Cognitive apprenticeship thus goes beyond domain knowledge (declarative knowledge such as facts, concepts and procedures of a subject) to also teach various types of strategic knowledge required for expert practice: heuristic strategies or "tricks of the trade"; control strategies or metacognitive strategies; and learning strategies.

However, in traditional apprenticeship the physical processes to be mastered are directly available for the students to observe. In order for students to observe the cognitve processes of the teacher, these must be made visible, in a strategy known as modelling (of a different kind than the modelling discussed in Section III). One approach is think aloud modelling, where teachers "describe what they are thinking and doing, why they are doing what they are doing, and verbalize their self-correction processes" [12]. According to Lave [10], modelling plays a crucial role in developing expertise in a certain domain as it helps students to form a conceptual model of the task before tackling it.

In cognitive apprenticeship, modelling is followed by five other key teaching strategies: coaching - the teacher asks questions and offers hints while the students deal with complex tasks; scaffolding - the teacher increases the complexity of the tasks and/or decreases the level of support as students become more adept; articulation - the students make their own thinking processes visible; reflection - the students compare their own thinking processes with those of the teacher and peers; and exploration students are encouraged to formulate and solve their own problems. These teaching strategies, in combination with authentic and collaborative tasks, constitute the essential elements of a cognitive apprenticeship environment.

Collins et al. [13] point out that "it is up to the teacher to identify ways in which cognitive apprenticeship can work in his or her own domain of teaching", and they provide a rich illustration of how cognitive apprenticeship has been implemented in three different subjects [9], including a course in mathematical problem solving [14]. For an overview of empirical research on implementing cognitive apprenticeship in different disciplines and at different educational levels, see [11].

As we see it, cognitive apprenticeship is based on an inductive approach to teaching and learning, where students learn complex cognitive skills by practicing tasks similar to those they wish to master (as in inquiry-based learning). However, the focus is additionally on how, in such a setting, the teacher can suitably align student thinking with expert thinking, by all means that the teacher can possibly think of. The key to this is to make both teacher and student thinking visible.

\section{Mathematical Modeling ANd Problem Solving}

In order to use mathematics to solve a real task, the first step is to translate relevant aspects of reality and the associated task into a mathematical representation, i.e. a model. We here include the ability to apply a mathematical perspective on real world phenomena. Modelling is therefore essential for applying mathematics to real world problems, see e.g. [15] and [16]. This requires some knowledge about mathematical representations and their properties. The modelling process is often described in terms of a modelling cycle, where the following steps are thought to be iteratively repeated to create refined models and answers to any questions: simplify the situation and "mathematize" it to create a mathematical model, work mathematically with this model, interpret and verify any results. There are many versions of the modelling cycle in the literature, see [17] for an overview. These are, however, rough descriptions of a complex process that is difficult to specify in detail, and which typically includes a number of non-standard situations to be resolved.

Therefore, throughout the modelling process, problemsolving abilities are required whenever the method for resolving the situation or problem is not known or easy to see. Such non-standard situations can then be handled without getting stuck, by systematically investigating the problem from different angles for improved understanding, and exploring possible ways forward. In mathematical problem solving, such activities have been characterized by Polya [18], in terms of heuristic strategies (draw a figure, define subgoals, consider special cases etc.), and globally in the following phases: understand the problem, devise a plan (select the approach), carry out the plan, look back. The phases are somewhat similar to the steps of the modelling cycle, and can likewise be interpreted iteratively in an exploratory process of failed attempts and deepened understanding. Schoenfeld [14] emphasizes how metacognitive aspects of control and different kinds of beliefs, attitudes and insights are critical for successful problem solving. Again, while characterizations of the problem solving process give some structure, it is difficult to specify the process in detail.

Modelling and problem solving are in our experience the main missing skills that our students need in order to use their mathematical knowledge in practice. This is because students are mostly trained in solving problems with given models and given methods, which is not sufficiently realistic. We also note that models, modelling and problem solving are fundamental concepts and processes that are useful beyond the mathematical domain.

However, teaching modelling and problem solving has its considerable challenges (see e.g. [19] and [20]). For example, it does not work to treat problem solving heuristics as algorithms, to be learned deductively. Instead, problem solving is more of an art that must be practised [18]. Moreover, we have found that the explicit teaching of modelling and problem solving in combination is very useful and natural. Modelling is the first and necessary step in applying mathematics, and since modelling is not strictly about right and wrong, progress is gradual and students feel that it is easier to be creative. This view is 
also supported by the models and modelling perspective on problem solving by Lesh et al. [21].

Modelling problems provide rich opportunities to show how mathematics is used in practice, and most basic mathematical competencies [2] are naturally practised, including communication skills and the use of computational tools. Modelling also stimulates the development of new mathematical concepts as needed. An aspect that is not extensively practised in our course is how to prove theorems, which is otherwise a central topic in mathematical problem solving, so the problem solving we practise has a somewhat different emphasis. However, it can certainly be of interest to prove properties of mathematical models (and of any new mathematical concepts), so this connection can be pursued if desired, and is facilitated by having basic problem solving skills already in place.

By teaching modelling and problem solving, we aim to overcome important shortcomings in engineering education as described in the introduction. At the same time, it means that we take a cognitive apprenticeship approach to engineering education.

\section{THE DESIGN OF THE COURSE}

The course is inquiry-based, and is designed around approximately 30 reasonably realistic problems that are solved in pairs. The problems illustrate different applications and ways to use mathematics. They also provide opportunities for learning modelling and problem solving skills. The course takes a broad view of modelling, and the problems are organized in six weekly modules, where each module focuses on a different type of model. This is illustrated in Figure 1, where the structure of a module is also shown (see [9] for details).

For some problems, Mathematica is useful, and it is a part of the course to become acquainted with this tool on a basic level. The course does not require any extensive reading, in order to focus on the skills to be learned.

In addition to the problems, the course offers unusually extensive supervision to support the students while they are solving the problems, as well as introductory and follow-up lectures for each module. These activities provide a rich platform for student-teacher interaction, and implement most of the identified elements of a cognitive apprenticeship.

\section{A. Designing the problems}

An important decision in the course has been to use a relatively large number of smaller problems - requiring one or a few hours to solve - rather than one or a few larger problems in a whole course as in PBL or a project course. This has been used to create a forced variation in applications, models and problem solving approaches, where differences and similarities can be observed. This makes it possible to learn and discuss modelling and problem solving patterns which are repeated and reinforced as the course progresses. With a sufficient number of problems it is also much easier to control what we want the students to learn.

Since the goal of the course is an increased ability to solve real world problems, of which only a few could fit in the course, many of the problems in the course are simplified real world problems (also a theoretical problem is considered as real if its solution contributes to the understanding of some topic).

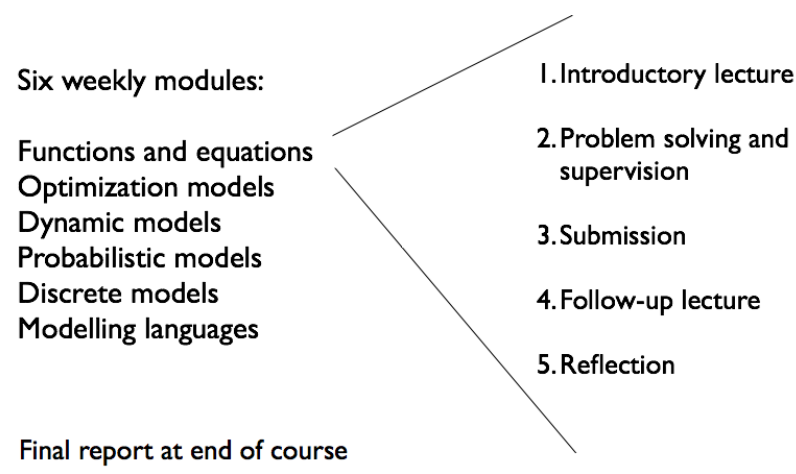

Figure 1. Overall structure of the course.

We then want the simplified problems to be realistic in that they retain important characteristics of real world problems [22]. We have considered that a problem should be a reasonable representative of a real world problem, its solution should be meaningful, and it should present similar cognitive challenges when solving it. Since real problems often cannot be solved with the immediate and straightforward application of some theory, the problem should be challenging both to understand and to solve, to stimulate modelling and problem solving skills as well as communication within the group and with the teacher.

Each problem then provides three kinds of important learning opportunities: what real world problems and their solutions look like, the basic concepts and methods required to solve them, and the skills required to find the solutions. The selection of problems has been made with respect to these three dimensions of learning [22], and we consider the relationship of the problem to these dimensions of learning as an integral part of the problem, which can be conveyed e.g. in the lectures. This also makes it possible to be more flexible in the simplification of real world problems, since lost aspects of the real world problem can still be discussed in class.

The problems have different character and complexity, depending on the specific topic, and depending on what we think the students are able to handle in each case (which requires some calibration). Some problems are more structured and have well-defined answers while others are more ill-structured and open-ended. We sometimes select problems with interesting links to theory or applications, or with surprising answers, to increase motivation.

\section{B. Supervision}

The problems are intentionally designed to be so challenging that most students are not able to solve them on their own, and continuous supervision is a very important element in the course. The supervision is conducted in a kind of workshop setting where the main teacher and the teaching assistants rotate and coach the students.

The unfamiliar and challenging problems force students to start thinking on their own, and to talk with each other and with the teachers. This makes their current thinking and especially their limitations clearly visible. So in terms of cognitive apprenticeship, the many hours of supervision provide rich opportunities for coaching, scaffolding, articulation and reflection.

As long as students get along with a specific problem, we try not to give more help than needed; if this help is not sufficient, students can get more help by asking again. 
In this way, we let them follow their own paths as much as possible, and at the same time ensure that they make some progress.

The style of supervision is mainly Socratic - it involves asking questions to probe student thinking, to help students clarify the situation they are in, or to point them in a useful direction. In this way, we foster metacognitive skills and indirectly teach a method that the students can use to supervise themselves.

We also remind students of general problem solving strategies, that problems cannot be solved in a single step, that they should not rush to the solution, and adress other individual difficulties as needed. We encourage the students and convince them that they are capable of solving the problems, if they are patient and learn to work in suitable ways. As the course progresses, there is sometimes room for more extended discussions where the teachers can reflect on the work done and share their experience.

\section{Introductory and follow-up lectures}

In the introductory lecture for each weekly module, we provide a general introduction relevant for the problems of the week, e.g. about the kind of models considered, with examples as needed - however without revealing specific methods for solving the problems.

As the course proceeds, we describe and characterize the modelling and problem solving processes in different ways. Initially, this helps to set the expectations around modelling and problem solving, and may provide useful hints. As the course proceeds this provides a language to talk about the processes we are interested in. This in line with making expert thinking visible in cognitive apprenticeship.

In the compulsory follow-up lecture, after submission of the weekly module, we provide collective feedback by presenting good solutions, and by discussing alternative approaches and common difficulties. We also as appropriate explain the background to the problems and highlight any interesting results. We generalize and present perspectives beyond single problems, for example by showing a related large-scale problem, making comparisons, or by noting the importance of certain models, methods and problem solving techniques.

With this follow-up lecture, it doesn't matter so much if the students didn't reach all the way to a solution of a problem. When they have spent time struggling with the problems, they are in a good position to appreciate and learn from the solutions. We encourage reflection by asking the students to compare their own solutions with the presented ones, and to consider what they might do differently in the future. This reflection is to be written as a part of the following module.

\section{Assessment}

To pass a weekly module, the most important requirement is that the group has seriously attempted to solve the problems, but they are not required to reach any final or correct answers. We also require that the facts are correct and that the presentation is acceptable. In practice, these requirements mean that if a student agrees to participate in the course, and spends a reasonable number of hours, she can feel confident to pass. This is important to make the students relax and take interest in the real challenges of the course. Otherwise, it would be very stressful to present ill-structured and difficult problems, which may go be- yond what a student is able to solve. It also reduces the motive for cheating.

By not formally grading the weekly modules and by providing significant collective feedback during the follow-up lectures, we are able to keep a normal course budget (we usually have about 100 students). Direct interaction with students has been heavily prioritized over time consuming marking and written feedback.

In order to pass the course, the weekly modules and a final report must be completed. The general purpose of the report is to let the students reconsider and reflect on the course, and it is up to each group to decide how and what to write. Some write a relatively straightforward summary, others make quite remarkable analyses and reflections. The final grade is determined by the final report and a rough assessment of the modules, based on given quality criteria [1]. Disagreements are unusual but are resolved in a dialogue, where students can improve their report whenever reasonable.

\section{SNAPSHOTS FROM THE COURSE}

To better convey how the various elements of our pedagogical design come into play, we here give an example of a teaching and learning sequence in the course. We also describe three more examples of problems in the course.

\section{A. Curve fitting problem}

In one of the first problems, the students are asked to find a curve that fits a number of points provided in a table. No systematic method for doing this has been presented, and many students are confused. However, by asking students who are stuck if they have drawn a figure, they make a plot of the points and begin to see how they might work (although it happens that some draw so carelessly that they start making false conclusions and are lost). The plot is shown in Figure 2.

After making the plot, those who so need are asked if they know of any mathematical functions. A common student question is: "Is it allowed just to do that?" By looking at the curvature, many students hypothesize the logarithmic function. When they ask for confirmation, we may ask what they think the value of the function should be at 0 and at infinity. They then usually discard their hypothesis by themselves, and continue with other functions. Another common student question is: "Is this good enough?" to which we ask if they are satisfied, and some students start to think about how the quality of a fit can be measured (if they are unaware of the least squares method). Some students do some polynomial approximation that they get out of Excel, giving a very good fit but with a complicated expression.

In the follow-up lecture, a simple formula with an excellent fit is presented, and different ways to find it are discussed (quite a few groups find this solution). We also consider how other alternatives can be discarded, or why they are not preferable. They also learn that what they have - or could have - discovered, is in fact one of Kepler's laws. This observation opens up for a short historical background and reflection on the nature of scientific discovery. 
PAPER

Teaching Mathematical Modelling and Problem Solving - A Cognitive ApPrenticeship Approach to...

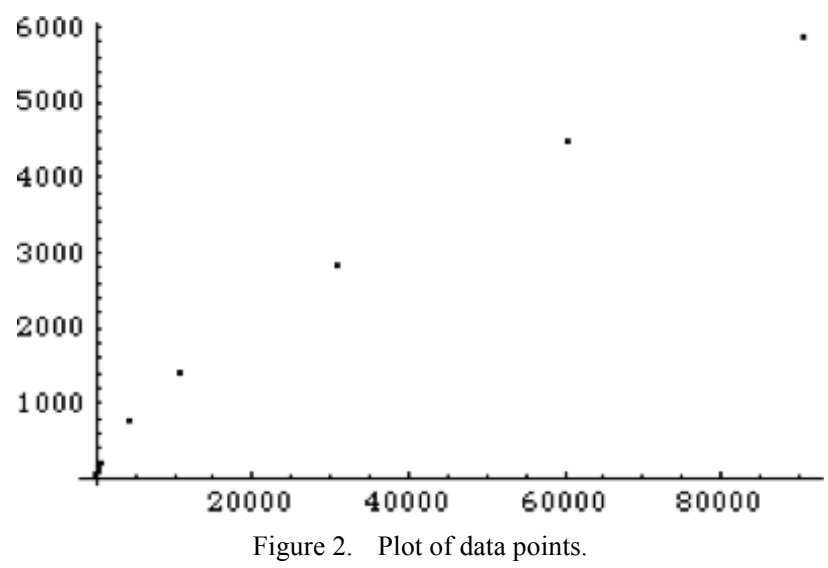

Note how this single problem meets multiple objectives: to introduce curve fitting; learning to develop your own problem solving strategy and discover the modelling cycle (which is not presented to the students before they solve this problem); to recollect basic mathematical functions and realize the importance of being systematic; to evaluate the quality of a model; to prepare for a later problem on the least squares method; and to provide a link to the history of science.

We would like to point out that in the design of a problem, it makes a huge difference how the theme of the problem is used. For example, we use this curve fitting problem to place the students in a problem solving situation where something is to be discovered by exploration. This is in line with situated learning theory and an inductive approach to teaching. It could be used more conventionally by first presenting the least squares method, providing the planet data, and asking the student to fit a given curve form to the data with this method. This would still be a "modelling problem", but it would provide a very incomplete understanding of what modelling is, and would not develop any problem solving skills. This is also emphasized in the models and modelling perspective, where the central distinction between an inductive and a deductive approach has been captured in the phrases making practice mathematical versus making mathematics practical [23].

We end this section by providing three more examples of problems in the course.

\section{B. Bridge problem}

As an example of a problem with a surprising answer, the students are asked to calculate the expected time of travel between two cities in a given road network, with some assumptions about how travel time varies with traffic intensity. The question is then to see how the expected travel time between two cities improves if an bridge is built, in addition to the already existing roads. However, it turns out that the travel time increases (this is known as Braess paradox). In the modelling, students need to think about traffic in terms of flow, understand driver behavior and model mathematically, and realize that the solution lies in establishing a criterion for an equilibrium. The problem also gives insights in how you can find a "mathematical perspective", in the relation between mathematics and common sense, and in the qualitative value of simple mathematical models.

\section{Bouncing balls problem}

One programming exercise is included in the course. The task is to create a graphical two-dimensional simulation of two balls of different size and weight, which move under the influence of gravity, and which may also collide with each other. This is relatively straightforward, but it requires some recollection of basic mathematics, a systematic approach where several subgoals need to be defined, and attention to details such as the proper definition of coordinate systems, angles and reference directions. Some students spend a lot of time without success because they are not careful with the mathematical details, and learn from that experience. Even without such difficulties, the exercise gives some perspective on the relation between pure mathematics, and the additional considerations required when you actually want something to work in a computer program such as a simulator. Some students patch mathematical errors with additional code, and are amazed when they realize that with the correct math most problems just disappear.

\section{Medical drug dosage problem}

This is an example of a relatively open modelling problem. The students are asked to find a way to calculate the dose and intake interval of a drug. No specific information or data is provided. Solving this problem involves deciding on relevant criteria, eliminating irrelevant factors, making assumptions including a model for how the concentration of a drug in the blood varies over time, understanding the dynamics of multiple intakes, and derivation of the appropriate formulas. If a too simple linear model of decay is used and assumed to be true, prescriptions as they are commonly written could lead to an unlimited increase of the concentration and death. So a better model is required. The problem is also an example of how you can sometimes proceed with a mathematical analysis in the absence of specific data or deep subject knowledge.

For a more exact formulation of these problems, and more problems, see [1]. Many of the problems have been created for this course, some are more classical.

\section{STUDENT IMPRESSIONS AND LEARNING}

In this section, we briefly discuss students' impressions of the course mainly based on an analysis of the course evaluations and the final reports. We also share some experiences from the supervision sessions. For a more extensive evaluation of what students learn in the course, see [24].

When students enter the course, many of them know more mathematics than they are able to use, and they do not trust their own ability to "think mathematically" [20]. They have little experience of modelling, tend to see formulas as given, and often see mathematics as something where form is more important than content. Many students do not expect the course to be useful, and expect even more complicated calculations than in previous courses.

When students are first confronted with the problems in the course, they are usually frustrated about them, that they are not clearly formulated, that there seems to be no immediate way to see how to solve the problems and that the time they spend on a problem goes out of control. The students do, as expected, experience difficulties related to modelling, such as how to best simplify a problem and how to mathematize. However, in the beginning of the 
course, the students are even more concerned with difficulties related to problem solving in general. In particular, they are not aware of the importance of understanding the problem and have difficulties in considering alternatives in the problem solving process [24]. Generally, students acknowledge that the problems are different from the problems that they have previously encountered. However, after some failed attempts, they begin to realize the complexity of the problem solving process, and begin to change.

The students generally consider both the supervision and the follow-up lectures as very important. One significant experience from the supervision is how students are restricted by a surprising number of fundamental misconceptions and expectations that hamper them in their progress, and how efficient the problems and the supervision are to reveal and remedy these. Why should we, for example, believe in the Pythagorean theorem? Common student answers are: "it is well known", "it seems to work on many triangles", and "there are several different mathematical proofs", This range of answers naturally leads to a fruitful discussion about fundamental concepts. In the first years of the course, before we had learned to clearly set the expectations in the beginning, a common remark was that "we waste half of the time to understand what it is we are supposed to do". With respect to working practices, many students are used to rush towards an answer without proper analysis; they are answer-focused [25], and expect that either they should see how to solve the problem very quickly, or they need to learn more advanced mathematics. A related difficulty is that many students do not recognize the importance of being careful. Students are often not aware of their limitations, because they have previously not encountered situations or problems that reveal them, or because they have not themselves understood the nature of their own behavior. That modelling problems are efficient tools to reveal students' thinking is also pointed out in [21].

To what extent the students learn on their own by solving the problems (the main emphasis in inquiry-based learning), and to what extent they learn from the teachers (the main emphasis in cognitive apprenticeship) differs a bit between students. Most students think both are very important, but some students seem to get along quite well by solving the problems on their own. However, to the extent that these students come to the supervision sessions, they (and the teacher) appreciate the more qualified discussions that become possible, although they may not be strictly necessary in order to reach the goals of the course.

After taking the course, most students express - but also demonstrate - a fundamental change in their abilities to "think mathematically", in their understanding of the nature of mathematics and its role in their future profession. The learned concepts and skills are considered as generally useful. The following comment is representative for many of the students: "For the first time during my studies I was able to connect the course both with previous courses as well as with the kind of problems I can expect in my profession as an engineer". Comments like "I have never before thought about where the formulas come from", and "The course has lifted me to an entirely new level" are common. One of the most commonly reported experiences is that modelling and problem solving show them a new and more creative side of mathematics that is not just about right and wrong. Moreover, the students are surprised to see how very "simple" mathematics can be used to solve apparently non-trivial problems, and how their prior knowledge of mathematics, in unexpected ways, turns out to be useful as steps in the problem solving process. For the first time, many students see how mathematics can be a part of their identity as engineers.

Students regard the course as one of the most important courses in their education, and that it is helpful in putting the pieces of their education together. It is considered demanding and at times also frustrating, although the percentage of students that pass is unusually high compared to other courses. Students ask for more courses like this one, and wonder why there weren't similar courses earlier in their education. In 2013, the students gave the course an average overall grade of 4.8 out of 5 . The course was recently awarded the Chalmers Pedagogical Prize.

\section{CONCLUDING THOUGHTS}

In this article, we have described the design of a course in mathematical modelling and problem solving. We have also tried to capture its role in engineering education and its general philosophy in terms of inquiry-based learning and cognitive apprenticeship. In the beginning of the course, students have little previous experience of mathematical modelling and problem solving and struggle in learning these skills. The single most important contribution of the course is that it exists, and that it aims to develop these generic skills that students do otherwise not sufficiently encounter. A key characteristic of the course is also that it has been designed entirely with the course objectives in mind, rather than starting from an idea of how courses usually are delivered, or a particular method of teaching.

One might say that the course and its problems represent an intermediate step between straightforward knowledge oriented courses and PBL-courses or projects. Compared to the former, this course has a much higher emphasis on methods and skills for approaching unfamiliar and non-trivial problems. Compared to the latter, the student encounters a wide range of simplified but realistic problems and a wide range of approaches, and learns to make appropriate distinctions and choices between them. So the controlled setting of this course, with a large number of varied problems that the teachers know well, can be expected to prepare the students for projects and other more independent work.

We see a remarkable development with respect to the students' modelling and problem solving skills. The students really see the value of these new skills, and acknowledge that it constitutes a new way of thinking for them. While teaching such skills can be challenging, we think that the kind of problems that we use together with a cognitive apprenticeship approach works very well. The extensive interaction with the students also makes the course stimulating for the teachers. We therefore conclude that this kind of course, or similar teaching, should be generally present in the engineering curriculum.

\section{REFERENCES}

[1] Wedelin, D., Course home page - mathematical modelling and problem solving (go via the personal home page of Dag Wedelin)

[2] Alpers, B. (Ed.), A framework for mathematics curricula in engineering education, Bussels: European Society for Engineering Education, 2013. 
[3] Litzinger, T., Lattuca, L. R., Hadgraft, R., \& Newstetter, W., "Engineering education and the development of expertise". Journal of Engineering Education, 100(1), 123-150, 2011, http://dx.doi.org/10.1002/j.2168-9830.2011.tb00006.x

[4] Mills, J. E., \& Treagust, D. F., "Engineering education: Is problem-based or project-based learning the answer?", Australasian Journal of Engineering Education, 3, 2-16, 2003.

[5] Stice, J., Teaching problem solving, TA handbook, Texas University, 1996.

[6] Adawi, T., Ingerman, Å., and Pendrill, A-M., "How mathematical is conceptual understanding?" Proceedings of Physics Teaching in Engineering Education conference, PTEE-2005, Brno, Czech Republic, 2005.

[7] Flegg, J., Mallet, D., \& Lupton, M., "Students' perceptions of the relevance of mathematics in engineering", International Journal of Mathematical Education in Science and Technology, 43(6), 2012. http://dx.doi.org/10.1080/0020739X.2011.644333

[8] Prince, M. J., and Felder, R. M., "Inductive teaching and learning methods: definitions, comparisons and research bases", Journal of Engineering Education, Vol. 95, pp. 123-138, 2006. http://dx.doi.org/10.1002/j.2168-9830.2006.tb00884.x

[9] Collins, A., Brown, J. S., \& Newman, S. E.,. "Cognitive apprenticeship: Teaching the craft of reading, writing, and mathematics", In L. B. Resnick (Ed.), Knowing, learning, and instruction: Essays in honor of Robert Glaser (pp. 453-494). Hillsdale, NJ: Lawrence Erlbaum Associates, 1989.

[10] Lave, J.. Cognition in practice: Mind, mathematics and culture in everyday life. Cambridge University Press, 1988. http://dx.doi.org/10.1017/CBO9780511609268

[11] Dennen, V. P., \& Burner, K. J., "The cognitive apprenticeship model in educational practice", Handbook of research on educational communications and technology, 425-439, 2007.

[12] Duncan, S. L., "Cognitive apprenticeship in classroom instruction: Implications for industrial and technical teacher education", Journal of Industrial Teacher Education, 33(3), 1996.

[13] Collins, A., Brown, J. S., \& Holum, A., "Cognitive apprenticeship: Making thinking visible", American Educator, 6(11), 38-46, 1991.

[14] Schoenfeld, A., Mathematical Problem Solving, Academic Press, 1985.

[15] Giordano, F., et.al., A first course in mathematical modeling, $4^{\text {th }}$ Ed., Brooks/Cole, 2008.

[16] Meerschaert, M., Mathematical modeling, $3^{\text {rd }}$ Ed, Academic Press, 2007.

[17] Borromeo Ferri, R. , "Theoretical and empirical differentiations of phases in the modelling process", Zentralblatt für Didaktik der
Mathematik, 38 (2), 86-95, 2006. http://dx.doi.org/10.1007/ BF02655883

[18] Polya, G., How to Solve It, Princeton University Press, 1945.

[19] Kaiser, G, Blum, W, Borromeo Ferri, R, and Stillman, G, editors, Trends in Teaching and Learning of Mathematical Modelling, Springer, New York, 2011. http://dx.doi.org/10.1007/978-94-0070910-2

[20] Schoenfeld, A.H., "Learning to think mathematically: Problem solving, metacognition, and sense-making in mathematics", Handbook for Research on Mathematics Teaching and Learning, D. Grouws (Ed.), New York: MacMillan, 1992.

[21] Lesh, R., \&. Doerr, H., Beyond constructivism: Models \& modeling perspectives on mathematics problem solving, learning, \& teaching, Mahwah, NJ: Lawrence Erlbaum, 2003.

[22] Wedelin, D., Adawi, T., "How to design small realistic problems experiences from a course in mathematical modelling and problem solving”, unpublished.

[23] Lesh, R., Yoon, C., \& Zawojewski, J., "John Dewey revisited: Making mathematics practical versus making practice mathematical”, In Lesh, R., Hamilton, E. \& Kaput, J (Eds.) Foundations for the future in mathematics education, Mahwah, NJ: Lawrence Erlbaum, 2007.

[24] Wedelin, D., Adawi, T., Jahan, T., Andersson, S., Teaching and learning mathematical modelling and problem solving, CISPEE 2013, Porto, Portungal, 2013.

[25] Booker G., "Thinking mathematically - making sense and solving problems", Proceedings of the $8^{\text {th }}$ international conference for the Mathematics Education into the 21st Century Project, Johor Bahru, Malaysia, 2005.

\section{AUTHORS}

D. Wedelin is with the Department of Computer Science and Engineering, Chalmers University of Technology, Gothenburg, Sweden. (e-mail: dag@chalmers.se).

T. Adawi is with the Division of Engineering Education Research, Department of Applied Information Technology, Chalmers University of Technology, Gothenburg, Sweden. (e-mail: adawi@chalmers.se).

This article is an extended and modified version of a paper presented at the CISPEE 2013 conference, held October 31 - November 01, 2013, in Porto, Portugal. Article received February 02, 2014. Published as resubmitted by the author 07 March 2014. 